\title{
EFEITO DA IRRIGAÇÃO, ÉPOCAS DE CORTE DA FORRAGEM E DOSES DE NITROGÊNIO SOBRE A QUALIDADE DE SEMENTES DE MILHETO (PENNISETUM $\operatorname{AMERICANUM(L.)~LEEKE)}{ }^{1}$
}

\author{
JOÃO BATISTA JORNADA DA JORNADA², RENATO BORGES DE MEDEIROS ${ }^{3}$, CARLOS EDUARDO DA SILVA PEDROSO², \\ JOÃO CARLOS DE SAIBRO ${ }^{4}$, MARCELO ABREU DA SILVA3.
}

\begin{abstract}
RESUMO - O trabalho foi conduzido com o objetivo de avaliar o efeito da irrigação, da épocas de remoção da forragem e de quatro doses de nitrogênio $(\mathrm{N})(0,50,100$ e $150 \mathrm{~kg} / \mathrm{ha})$ sobre a qualidade de sementes de milheto (Pennisetum americanum (L.) Leeke). Os cortes foram realizados a uma altura de $20 \mathrm{~cm}$, aos 41 dias apos semeadura, na E1 e aos 51 na E2. Foram determinados o peso de mil sementes (PMS), o teor de nitrogênio, a germinação e o vigor pelos testes de: condutividade elétrica, envelhecimento acelerado a 48 e 72 horas, primeira contagem de germinação e teste de emergência a campo. A remoção precoce da forragem (E1) afeta positivamente a qualidade das sementes de milheto. Aplicações de nitrogênio podem contribuir para a melhoria da qualidade fisiológica da semente de milheto e associadas à irrigação proporcionam sementes com maior capacidade de emergência.O conteúdo de nitrogênio das sementes não e afetado em função da aplicação de nitrogênio em cobertura.
\end{abstract}

Termos para indexação: pastagem anual, armazenamento de sementes, testes de vigor, qualidade fisiológica.

\author{
EFFECT OF IRRIGATION, CLIPPING DATE AND NITROGEN FERTILIZATION RATES \\ ABOUT THE SEED QUALITY OF PEARL-MILLET (Pennisetum americanum (L.) Leeke)
}

\begin{abstract}
A field trial was carried with the objective to evaluate the effect of irrigation clipping date and nitrogen $(\mathrm{N})$ fertilization rates on seed quality of pearl-millet (Pennisetum americanum (L.) Leeke). The experiment was arranged in a randomized split-split-plot design with four replications. The clippings were done at $20 \mathrm{~cm}$ height after 41 and 51 days after seeding. It was determined: thousand seed weight (PMS), nitrogen rate, germination test and vigour tests: electric conductivity, accelerated aging in 48 and 72 hours, first germination counting and emergency test at field were done. Early forage removal (E1) affected positively the quality of the pearl millet seeds, which showed higher values in the germination tests, accelerated aging in 72 hours and on the first germination counting and lower values in the electric conductivity test. The seed nitrogen content was not affected by nitrogen applications. The higher nitrogen efficiency occurs in presence of irrigation.
\end{abstract}

Index terms: agronomic practices, seed storage, vigour tests and fisiology quality.

\footnotetext{
${ }^{1}$ Submetido em 03/04/2006. Aceito em 08/03/2007. Parte da dissertação de mestrado do primeiro autor apresentada à Universidade Federal do Rio Grande do Sul (UFRGS).
}

${ }^{2}$ Engenheiro Agrônomo, MSc, UFRGS, jornadajb@ig.com.br

\footnotetext{
${ }^{3}$ Engenheiro Agrônomo, Dr., professor adjunto, Departamento de Plantas Forrageiras e Agrometeorologia (DPFA), UFRGS, Av Bento Gonçalves, 7712, Bairro Agronomia, Cep. 91.540-000, Porto Alegre, RS, Brasil.

${ }^{4}$ Professor aposentado, colaborador convidado, DPFA, UFRGS.
} 


\section{INTRODUÇ̃̃O}

A utilização de gramíneas anuais de verão para a alimentação dos rebanhos é cada vez mais freqüente nas regiões sul e centro-oeste do Brasil. Dentre as espécies que compõem este grupo, o milheto (Pennisetum americanum (L.) Leeke) tem se destacado devido à boa adaptação as condições edafoclimáticas e a alta produção de forragem com excelente qualidade, sendo utilizado especialmente em pastejo direto ou para silagem.

O sucesso do estabelecimento de novas áreas com esta espécie depende de uma satisfatória produção de sementes. Em sistemas de produção de sementes é cada vez mais importante o conhecimento da qualidade fisiológica das mesmas em resposta a práticas de manejo. Estas por sua vez devem apresentar boa qualidade fisiológica a qual pode ser influenciada por práticas de manejo, dentre elas a adubação nitrogenada, irrigação e o corte da forragem baseado no estádio de desenvolvimento da cultura.

Para isso dispõe-se de testes laboratoriais sendo que o mais utilizado é o teste de germinação. Este teste de germinação tem por objetivo obter informações sobre a qualidade das sementes para fins de semeadura a campo e fornecer dados que possam ser usados, juntamente com outras informações, para comparar diferentes lotes de sementes (Brasil, 1992). Porém este teste nem sempre revela diferenças na qualidade fisiológica dos lotes, que podem se manifestar nas condições adversas do campo ou durante o armazenamento (Marcos Filho, 1981).

Em adição às informações obtidas pelo teste de germinação, os fisiologistas de sementes passaram a estudar o vigor como uma característica capaz de fornecer dados complementares sobre qualidade de sementes. Os testes de vigor têm sido muito utilizados pela indústria como uma ferramenta para a determinação da qualidade fisiológica das sementes (Krzyzanowski et al., 1999). Estes testes objetivam avaliar ou detectar diferenças significativas na qualidade fisiológica de lotes com germinação semelhante distinguindo, com segurança, lotes de alto e baixo vigor.

Existem vários testes de vigor, dentre eles o de envelhecimento acelerado, condutividade elétrica e testes baseados no desempenho das plântulas. $\mathrm{O}$ teste de envelhecimento acelerado tem como base o fato de que a taxa de deterioração das sementes é aumentada consideravelmente através de sua exposição a níveis muito adversos de temperatura e umidade relativa, considerados os fatores ambientais preponderantes na intensidade e velocidade de deterioração (Krzyzanowski et al., 1999). Garcia e Menezes (1999) realizaram teste de envelhecimento precoce com objetivo de determinar as condições de temperatura e umidade adequadas para avaliação de qualidade de lotes de sementes de azevém, aveia preta e milheto. Segundo estes autores, mantendo a temperatura a $41^{\circ} \mathrm{C}$ e a umidade relativa em $100 \%$ de UR do ar, o período de 24 horas estratifica lotes de sementes de aveia preta pelo vigor. O período de envelhecimento precoce para estratificar lotes de sementes de milheto e azevém deve ser de 24 a 48 horas e períodos de 72 a 120 horas são muito drásticos para essas três espécies e impedem a estratificação de lotes pelo vigor.

$\mathrm{O}$ valor da condutividade elétrica, medido em função da quantidade de lixiviados na solução de embebição das sementes, está, por sua vez, diretamente relacionado à integridade das membranas celulares, tendo, assim, sido proposto como um parâmetro de avaliação do vigor de sementes (Matthews e Powell, 1981; Hampton e Tekrony, 1995). A capacidade de reorganização das membranas celulares e de reparar certo nível de dano é maior para sementes de mais alto vigor, em comparação àquelas de menor nível de vigor. Como conseqüência, tem-se menor valor para a condutividade elétrica da solução de embebição de sementes de maior vigor comparada àquelas de menor vigor (Matthews e Powell, 1981).

Quanto a primeira contagem de germinação o teste baseiase no princípio de que as amostras que apresentam maior percentagem de plântulas normais, na primeira contagem, estabelecida pelas Regras para Análise de Sementes - RAS (Brasil, 1992), são mais vigorosas (Krzyzanowski et al., 1999).

Dentro deste contexto, foi conduzido um trabalho na Estação Experimental Agronômica da Universidade Federal do Rio Grande do Sul - UFRGS objetivando avaliar o efeito da irrigação, épocas de corte e doses de nitrogênio sobre a qualidade fisiológica das sementes de milheto, pelos de testes de germinação e vigor de sementes.

\section{MATERIAL E MÉTODOS}

O experimento foi conduzido na Estação Experimental Agronômica da Universidade Federal do Rio Grande do Sul (EEA - UFRGS), município de Eldorado do Sul, Rio Grande do Sul, com altitude de $46 \mathrm{~m}$ do nível do mar. O clima, segundo a classificação de Köppen, é do tipo Cfa (subtropical úmido com verão quente). Os dados meteorológicos como precipitação $(\mathrm{mm})$, temperatura média $\left({ }^{\circ} \mathrm{C}\right)$ e radiação solar global (cal $\left./ \mathrm{cm}^{2} / \mathrm{dia}\right)$ foram coletados da Estação Meteorológica do Departamento de Plantas Forrageiras e Agrometeorologia da UFRGS, situada a 100 metros do local do experimento (Tabela 1). O experimento foi estabelecido 
em solo da unidade de mapeamento Arroio dos Ratos, classe taxonômica Plintossolo, apresentando a seguinte composição química: $\mathrm{pH}-\mathrm{H}_{2} \mathrm{O}(1: 1)=5,3 ; 22 \%$ de argila; $1,2 \%$ de matéria orgânica; 18 mg/l de $\mathrm{P}$ disponível; 130 mg/l de K trocável e $0,3 \mathrm{cmol}_{\mathrm{c}} / 1$ de alumínio trocável.

TABELA 1. Precipitação pluviométrica, temperatura média do ar e radiação solar global média durante o período experimental. EEA/UFRGS, Eldorado do Sul, RS, 2000/01.

\begin{tabular}{|c|c|c|c|c|c|c|}
\hline & \multicolumn{2}{|c|}{ Precipitação (mm) } & \multicolumn{2}{|c|}{ Temp. média do $\operatorname{ar}\left({ }^{\circ} \mathrm{C}\right)$} & \multicolumn{2}{|c|}{$\mathrm{RSGM}^{*}\left(\mathrm{cal} / \mathrm{cm}^{2} / \mathrm{dia}\right)$} \\
\hline & Ocorrida & Normal** & Ocorrida & Normal & Ocorrida & Normal \\
\hline Janeiro & 171,3 & 114,8 & 24,2 & 24,7 & 457 & 495 \\
\hline Fevereiro & 121,5 & 107,6 & 25,0 & 24,8 & 451 & 444 \\
\hline Março & 143,7 & 106,7 & 24,2 & 23,3 & 103 & 393 \\
\hline Abril & 290,9 & 101,8 & 20,2 & 19,7 & 277 & 319 \\
\hline
\end{tabular}

* Radiação solar global média

** Normais : padrão do período de 1970 a 1989 para precipitação e temperatura média e 1968 a 1988 para RSGM para Eldorado do Sul - RS.

O experimento constituiu-se num fatorial $2 \times 2 \times 4$. O delineamento experimental utilizado foi parcela subsubdividida com as parcelas principais arranjadas em blocos casualizados com quatro repetições. Os fatores estudados foram: irrigação (irrigado e não irrigado), alocados nas parcelas principais, duas épocas de remoção ou corte da forragem (E1 - remoção de aproximadamente $50 \%$ dos ápices dos meristemas apicais dos perfilhos primários e E2 - remoção de 75\%) alocados nas subparcelas e quatro doses de nitrogênio $(\mathrm{N})(0,50,100$ e $150 \mathrm{~kg} / \mathrm{ha})$ nas subsubparcelas. As sub-subparcelas tinham dimensão de 8 $\mathrm{x} 3,2 \mathrm{~m}$, com 8 linhas espaçadas de $0,4 \mathrm{~m}$, considerando como bordadura duas linhas em cada extremidade lateral e $1 \mathrm{~m}$ em cada cabeceira. A semeadura direta foi realizada no dia 29/12/00. Os tratamentos de N, na forma de uréia, foram parcelados em duas aplicações iguais, a primeira em 16/01/2001 e a segunda uma semana após os cortes em E1 e E2. Os cortes foram realizados a uma altura de $20 \mathrm{~cm},(E 1=09 / 02$ e E2=19/02). A irrigação, por aspersão, foi aplicada baseada no monitoramento da diferença entre a precipitação e a evaporação do tanque classe A. Quando esta atingia $30 \mathrm{~mm}$ de déficit indicava que uma irrigação deveria ser aplicada, procedimento este adaptado de Rojas (1998). As irrigações de 30mm foram efetuadas em 23/02 e 02/03/01. A colheita de sementes foi realizada nos dias 30/04 e 01/05/2001 nos tratamentos E1 e E2, respectivamente. Primeiramente, procedeu-se o corte apenas das panículas, na área útil, com o auxílio de uma tesoura. As panículas foram acondicionadas e posteriormente secadas em um secador de leito fixo a uma temperatura de (aproximadamente) $33 \pm 2^{\circ} \mathrm{C}$ durante 72 horas. Após o material foi trilhado e limpo com o auxílio de uma trilhadeira estacionária e de um sistema de ventilador e peneiras. A amostragem do material para a realização dos testes de vigor foi realizada de acordo com RAS (Brasil, 1992). Para a determinação do peso de mil sementes (PMS) foram utilizadas oito subamostras de 100 sementes cada, da porção semente pura (Brasil, 1992). Para a avaliação do teor de $\mathrm{N}$ na semente foi utilizada uma amostra de aproximadamente $5 \mathrm{~g}$ de sementes puras. Estas sementes foram moídas e enviadas ao laboratório de análises do Departamento de Zootecnia da UFRGS para a análise pelo método de KJELDHAL, descrito por Bremner (1965). O teor de proteína bruta foi estimado multiplicandose o teor de $\mathrm{N}$ encontrado pelo fator 6,25. Aos 90 e 173 dias após a colheita de sementes, foram realizados testes de germinação conforme RAS (Brasil, 1992). O segundo teste visou comparar o resultado com a germinação das sementes submetidas ao teste de envelhecimento acelerado a 48 e 72 horas e com o primeiro teste de germinação realizado 90 dias após a colheita. Também neste teste foram realizadas duas contagens: uma no $3^{\circ}$ dia e outra no $7^{\circ}$ dia. Esta primeira contagem serviu como um teste de vigor baseado no princípio de que os lotes com maior porcentagem de germinação na primeira contagem são os mais vigorosos (Brasil, 1992). O teste de condutividade elétrica foi realizado entre os dias 03 e 11/09/2001. Utilizaram-se 64 subamostras da fração semente pura correspondendo a todos os tratamentos com quatro repetições. O teste foi realizado conforme metodologia descrita em Krzyzanowski et al.(1999) sendo o resultado expresso em mhos. $\mathrm{cm}^{-1} \cdot \mathrm{g}^{-1}$.O teste de envelhecimento acelerado a 48 e 72 horas foi realizado entre os dias 24/10 e 1\%11 conforme Krzyzanowski et al.(1999). Para a realização do teste de emergência a campo foi retirada uma amostra de 100 sementes da fração semente pura. As sementes foram 
semeadas em bandejas de alumínio a uma profundidade de quatro $\mathrm{cm}$ e cobertas com terra oriunda da área experimental. As bandejas foram mantidas em bancadas de $1 \mathrm{~m}$ de altura, em casa de vegetação, sendo mantida umidade adequada. Para a análise estatística os dados foram submetidos à análise de variância. Os efeitos de irrigação e corte, quando significativos, foram submetidos ao teste de Duncan sendo o nível mínimo de significância aceito de 5\%. Quanto ao efeito de nitrogênio (quantitativo), quando significativo, foi submetido à análise de regressão testando-se os modelos linear e quadrático, em busca de um modelo que melhor expressasse esta relação, com nível de significância de 5\%. As análises foram efetuadas pelo programa SANEST (Zonta e Machado, 1984).

\section{RESULTADOS E DISCUSSÃO}

O período de condução do experimento foi caracterizado por precipitação elevada sendo esta, em alguns períodos, bem acima da média histórica (Tabela 1). Porém, houve um pequeno período de déficit hídrico entre o final de fevereiro e início de março, o que determinou a aplicação de duas irrigações de $30 \mathrm{~mm}$. No que se refere à temperatura e à radiação, do ponto de vista meteorológico, pode ser considerado como típico da região.

A remoção da forragem no estádio vegetativo baseada no monitoramento da altura do meristema apical dos perfilhos principais teve influência $(\mathrm{P}<0,05)$ sobre a qualidade das sementes de milheto manifestada através do teste de germinação, teste de condutividade elétrica, teste de envelhecimento acelerado a 72 horas e teste de primeira contagem de germinação.

A porcentagem de germinação nos testes realizados aos 90 e 173 dias após a colheita foi maior quando a forragem foi cortada precocemente (E1) (Tabela 2). Observa-se também que, mesmo com as sementes acondicionadas em geladeira, houve um decréscimo na porcentagem de germinação de $10 \mathrm{e}$ $11 \%$ para E1 e E2 respectivamente, indicando que as sementes desta espécie são muito vulneráveis à deterioração.

TABELA 2. Efeito da época de corte da forragem sobre a qualidade das sementes de milheto, avaliada pelo teste de germinação, teste de primeira contagem e teste de envelhecimento acelerado a 48 e 72 h. EEA/UFRGS, Eldorado do Sul, RS, 2000/01.

\begin{tabular}{|c|c|c|c|c|c|}
\hline \multirow{3}{*}{ Épocas de corte } & \multicolumn{3}{|c|}{ Germinação } & \multirow{2}{*}{\multicolumn{2}{|c|}{ Envelhecimento Acelerado }} \\
\hline & \multirow[t]{2}{*}{$90 \mathrm{DAC}$} & \multicolumn{2}{|c|}{$173 \mathrm{DAC}^{* *}$} & & \\
\hline & & $1^{\mathrm{a}}$ cont. & Cont. final & $48 \mathrm{~h}$ & $72 \mathrm{~h}$ \\
\hline E1 & $80 a^{*}$ & $15 \mathrm{a}$ & $70 \mathrm{a}$ & $54 \mathrm{a}$ & $50 \mathrm{a}$ \\
\hline E2 & $77 \mathrm{~b}$ & $11 \mathrm{~b}$ & $66 \mathrm{~b}$ & $44 \mathrm{a}$ & $34 \mathrm{~b}$ \\
\hline Média & 79 & 13 & 68 & 49 & 42 \\
\hline
\end{tabular}

* Médias seguidas de mesma letra na coluna não diferem entre si pelo teste de Duncan a $5 \%$ de probabilidade.

** DAC $=$ Dias após a colheita

*** Teste executado 173 DAC

A estimativa do vigor pela $1^{\text {a }}$ contagem, realizada no terceiro dia de germinação, também evidenciou a superioridade do tratamento E1 sobre E2 (Tabela 2). Esta resposta pode estar associada a uma maior proporção de sementes originadas de perfilhos primários em E1 do que em E2. O teste de primeira contagem baseia-se no princípio de que as amostras que apresentam maior porcentagem de plântulas normais, na primeira contagem, são as mais vigorosas (Brasil, 1992). Assim como nos demais testes de vigor, o corte removendo $55 \%$ dos meristemas apicais (E1) apresentou uma semente de maior vigor. Este vigor pode ser atribuído ao rebrote mais vigoroso e das reservas orgânicas das plantas.
$\mathrm{O}$ teste de envelhecimento acelerado (EA) realizado por um período de $48 \mathrm{~h}$ não estratificou as sementes pelo vigor (Tabela 2), porém quando realizado em $72 \mathrm{~h}$ revelou um maior vigor para as sementes oriundas do tratamento $\mathrm{E} 1$ confirmando o resultado obtido no teste de primeira contagem. Em todos os casos as sementes procedentes da forragem removida na primeira época de corte (E1) apresentaram porcentagem de germinação superior às que receberam o corte em E2. Houve uma redução progressiva na germinação com o aumento do período de envelhecimento, concordando com Garcia e Menezes (1999). Porém observando a Tabela 2 a redução desta porcentagem de germinação é proporcionalmente menor em E1 do que em E2, inferindo que as sementes em 
E1 apresentam maior resistência ao teste e, portanto maior vigor que as E2.

Quanto ao teste de condutividade elétrica, houve resposta à adubação nitrogenada. Não havendo um modelo de regressão que expressasse significativamente o resultado, procedeu-se o teste de comparação de médias (Tabela 3). O teste de condutividade elétrica baseia-se no princípio de que quanto maior a condutividade maior é a permeabilidade da membrana e, portanto menor é o vigor. Os dados da Tabela 3 mostram que somente na ausência de nitrogênio ocorreu a maior condutividade, indicando que pequenas doses de nitrogênio são suficientes para aumentar o vigor das sementes. Com relação à época de corte, as sementes cuja forragem foi cortada removendo $55 \%$ dos meristemas apicais dos perfilhos principais (E1) apresentaram menor condutividade $\left(39,36 \mu \mathrm{mhos} \cdot \mathrm{cm}^{-1} \cdot \mathrm{g}^{-1}\right)$ e portanto maior vigor que E2 $(49,81$ $\mu$ mhos.cm $\left.{ }^{-1} \cdot \mathrm{g}^{-1}\right)$.

TABELA 3. Efeito da adubação nitrogenada sobre a qualidade das sementes de milheto, avaliada pela porcentagem de $\mathrm{PB}$ na semente e pelo teste de condutividade elétrica da solução de embebição das sementes. EEA/UFRGS, Eldorado do Sul, RS, 2000/01.

\begin{tabular}{|c|c|c|}
\hline $\begin{array}{c}\text { Doses de N } \\
(\mathrm{kg} / \mathrm{ha})\end{array}$ & $\begin{array}{c}\mathrm{N} \text { na semente } \\
(\%)\end{array}$ & $\begin{array}{c}\text { Condutividade } \\
\text { elétrica } \\
\left(\mu \mathrm{mhos} \cdot \mathrm{cm}^{-1} \cdot \mathrm{g}^{-1}\right)\end{array}$ \\
\hline 0 & $1,56 \mathrm{a}^{*}$ & $49,67 \mathrm{a}$ \\
\hline 50 & $1,54 \mathrm{a}$ & $42,87 \mathrm{~b}$ \\
\hline 100 & $1,55 \mathrm{a}$ & $43,15 b$ \\
\hline 150 & $1,53 \mathrm{a}$ & $42,65 \mathrm{~b}$ \\
\hline Média & 1,55 & 44,59 \\
\hline
\end{tabular}

* Médias seguidas de mesma letra na coluna não diferem entre si pelo teste de Duncan a $5 \%$ de probabilidade.

Quanto à porcentagem de $\mathrm{N}$ na semente, não houve resposta às doses de nitrogênio aplicado. A literatura é escassa sobre a remoção de $\mathrm{N}$ pela semente ou a recuperação desse elemento em espécies de gramíneas. Esta ausência de resposta pode ser atribuída à diluição do $\mathrm{N}$ na planta em conseqüência do aumento da produção total de matéria seca de forragem, uma maior porcentagem de proteína bruta (PB) na mesma, além de um incremento de sementes (Greenwood et al., 1990). Embora o caminho percorrido pelo $\mathrm{N}$ não tenha sido determinado, indiretamente supõe-se que houve uma maior diluição do $\mathrm{N}$ quando foi utilizada uma dosagem maior, pois ocorreu um incremento na produção de MS de forragem, uma maior porcentagem de PB na mesma, além de um incremento de sementes, conforme demonstraram estes autores.

Quanto ao teste de emergência a campo a análise da variância revelou significância para a interação irrigação $\mathrm{x}$ doses de N. Nenhum modelo de regressão foi significativo para explicar esta interação e os dados são apresentados na Tabela 4. Não houve diferença significativa entre a aplicação ou não de nitrogênio dentro de cada nível do fator irrigação. Quanto à aplicação de $\mathrm{N}$, esta foi mais eficiente na presença de irrigação.

TABELA 4. Efeito de interação irrigação $\mathrm{x}$ doses de $\mathrm{N}$ sobre a porcentagem de emergência de plântulas de milheto a campo. EEA/UFRGS, Eldorado do Sul, RS, 2000/01

\begin{tabular}{ccc}
\hline \multirow{2}{*}{$\begin{array}{c}\text { Doses de } \mathrm{N} \\
(\mathrm{kg} / \mathrm{ha})\end{array}$} & \multicolumn{2}{c}{ Irrigação } \\
\cline { 2 - 3 } & Não irrigado & Irrigado \\
\hline 0 & $54 \mathrm{Aa}^{*}$ & $61 \mathrm{Aa}$ \\
50 & $54 \mathrm{Ba}$ & $66 \mathrm{Aa}$ \\
100 & $52 \mathrm{Ba}$ & $61 \mathrm{Aa}$ \\
150 & $53 \mathrm{Ba}$ & $59 \mathrm{Aa}$ \\
\hline Média & 53 & 61 \\
\hline
\end{tabular}

* Médias seguidas de mesma letra maiúscula (linha) e minúscula (coluna) não diferem entre si pelo teste de Duncan a 5\%.

O resultado desta variável parece um pouco contraditório com os observados nos outros testes de vigor realizados em laboratório. Porém, Krzyzanowski et al. (1999) relatam que a relação entre os resultados de testes de laboratório e a emergência das plântulas a campo depende diretamente das condições de ambiente e dos procedimentos adotados para a semeadura. Acredita-se que a metodologia utilizada no teste, com as sementes colocadas a quatro centímetros de profundidade e o solo da área experimental, não foram suficientemente drásticos para descriminar o vigor das sementes, podendo ter contribuído para o resultado, necessitando de condições um pouco mais adversas, dentro de um certo limite, como maior profundidade de semeadura, para a semente expressar o seu vigor.

\section{CONCLUSÕES}

Pelos resultados dos teste de avaliacao da qualidade é possivel concluir que sementes provenientes de áreas com uma 
maior proporção de perfilhos principais são mais vigorosas e, portanto apresentam maior potencial de estabelecimento nas condições de campo.

Aplicações de nitrogênio podem contribuir para a melhoria da qualidade fisiológica da semente de milheto e associadas à irrigação proporcionam sementes com maior capacidade de emergência.

O conteúdo de nitrogênio das sementes não e afetado em função da aplicação de nitrogênio em cobertura.

\section{REFERÊNCIAS}

BRASIL. Ministério da Agricultura e Reforma Agrária. Regras para análise de sementes. Brasília: SNDA/DNDV/ CLAV. 1992. 365p.

BREMNER, J.M. Total nitrogen. In: BLACK, C.A. (Ed.) Methods of soil analysis. Madison: American Society of Agronomy, 1965. Pt. 2, cap. 83, p. 1149-78.

GARCIA, D.C.; MENEZES, N.L. Teste de envelhecimento precoce para sementes de azevém, aveia preta e milheto. Ciência Rural, Santa Maria, v.29, n.2, p.233-237, 1999.

GREENWOOD, D.J.; LEMAIRE, G.; GOSSE, G.; CRUZ,
P.; DRAYCOTT, A.; NEETESON, J.J. Decline in percentage Nof $\mathrm{C}_{3}$ and $\mathrm{C}_{4}$ crops with increasing plant mass. Annals of Botany, London, v.66, p. 425-436, 1990.

HAMPTON, J.G.; TEKRONY, D.M. (Ed.) Handbook of vigour test methods. 3 ed. Zurich: The International Seed Testing Association, 1995. 117p.

KRZYZANOWSKI, F.C. et al. (Coord.) Vigor de sementes: Conceitos e testes. Londrina: ABRATES, 1999. 218p.

MARCOS FILHO, J. Qualidade fisiológica de sementes de soja. Pesquisa Agropecuária Brasileira, Brasília, v.16, n.3, p.405-415, 1981.

MATTHEWS, S.; POWELL, A.A. Electrical condutctivity test. In: PERRY, D.A. (Ed.) Handbook of vigour test methods. Zurich: ISTA, 1981. p. 37-42.

ROJAS, C.A.L. Alterações físico-hídricas de um podzolico em função do manejo do solo. 1998. 76 f. Dissertação (Mestrado) - Programa de Pós-graduação em Fitotecnia, Faculdade de Agronomia, Universidade Federal do Rio Grande do Sul, Porto Alegre, 1998.

ZONTA, E. P.; MACHADO, A. A. Sistema de análise estatística para microcomputadores (SANEST). Pelotas: UFPel, 1984. 